of Muleod's procedure, which I consider important, are hirtefly (1) non excision of the sac and (2) omclu-ion of the ling, with the ends of the catgut emploved for its transfixion and deligation. In this way the wound, in uncomplicited cases, is small, the catgut cannot sip off the sa: and the correct position of the stu ap in the ceutre of the ring is secured. I have recently operated in this manner on nine cases of liernia in hospital, in all of which the results were as go ud as in those reported. Under proper autiseptic management, without which the operation would be in possible, the wound heals at once, and consolidation of the ring is complete in fro.n eight to ten days.

Isahore.

\section{ON CHEYNE-STOKES' RESPIRATION.}

\section{BY F. M. PUDDICOMBE, L.R.C.P. LOND., \&c.}

SEEING that the above subject has been brought before the notice of the profession once more by Dr. Paterson in The LANCeT of January 20th, I venture to submit the particulars of the following case which has been under my care for some time past, and which presents several points worthy of notice.

S. E-, aged sixty-four, deaf and dumb, a brewer's labourer, with no family history, and no history of the patient's past life can be traced, with the exception that he was given to fits of intemperance. On January 29 th he was brought to the Teignmouth Infirmary in a state of insensibility, the limbs motionless, and the body cold; pupils somewhat contracted but answered to light, and the pulse was slow but weak. He had been found in this condition in a yard adjoining the brewery about an hour previously. Hot bottles were applied to the feet, he having been put to bed, and soon he was able to move slightly, when it was found that he was paralysed on the right side. No reflex movements could be produced on tickling the right foot. A short time after this he resisted all attempts to feed him, and we were obliged to use force during the rest of the day in order to make him take small quantities of nourishment.-30th: Has passed a restless night, snoring loudly whenever he dropped to sleep for a few minutes. He has passed some urine in the bed, but seems to have some control over his bladder. Has taken beef-tea and milk willingly, but latterly it has returned. Has had an ice-bag applied to his head and blisters behind his ears. Although there seemed to be some improvement this morning, he is decidedly worse to-night, and is very restless. - 31st: Sickness continues. Pulse is full and slow (56) this morning. Has used a bottle to pass urine in. Has retained a small quantity of heef-tea mixed with ice and lime-water. Bowels confined. Temperature $99.8^{\circ}$ this evening. - Feb. lst: Sickness stopped; temperature $98^{\circ} 6^{\circ}$. Seems better; appears to be conscious. The bowels have acted after an enema. Five grains of the bromide of potassium to be taken every five hours. - 2nd: The same. - 3rd : Rather lower this morning, but takes beef-tea and milk willingly. This evening, for the first time, my attention has been drawn to a most peculiar form of breathing. It much resembled that related by Dr. Paterson; the ascending and descending respiratory acts being well marked; the crisis, so to speak, consisting of a long-drawn, violent, and noisy respiration. Each breath was accompanied as a rule with stertor, even to the last of the descending series, the noise of the last breath somewhat resembling that made by the escape of the last water from a bath by a waste-pipe-a peculiar sucking noise. The pause would then take place, and would last from ten seconds to a minute, the duration varying greatly; the breathing would then recommence, softly at first as a rule, and then louder and louder, but sometimes it would begin again with a sudden violent and noisy effort. The number of ascending and descending respiratory acts numbered on an average seven to ten of each.

It would be superfluous to give a detailed account of the daily progress of the case. Sulfice it to say that no material improvement took place; indeed, little or no alteration could be observed for miny days, until, on the $19 \mathrm{th}$, when, though he seemed on the whole to be much weaker, reflex movements were readily induced by tickling the feet. 24th : The pauses still continue, though not so markedly as before; they have been observed several times during the daytime for the past few days, but only when sleeping, whereas at first they were only noticed at night.-26th The patiest is much weaker. He can only be made to swallow with dilliculty, and each attempt is attended with visleut couching. Uuly once or twice has the peculiar resuiration been observed during the past twenty four hours, -27th: The patient is very much worse, and apparently sinking fast. The character of the respiration is entirely changed ; there are no pauses, but he breathes with stertor, fifty respirations to the minute. All the patient's urise since the previous day has been passed under him, and he setms quite unconscious. Feeding (beyond wetting his lips with a feather dipped in milk) is out of the question. At 10 P.I. I was called by the nurse, who said the patient was dying. His respirations were sixty in the minute. The pulse could not be felt. The breathing gradually became slower and weaker, and after a couple of pauses of about a minute each (such as may often be noticed in dying people) it finally stopped. The temperature of the body at the time of death was $1026^{\circ}$. The urine could not be collected for the past two days.

Before giving an account of the autopy I will mention several facts in connexion with the case, which, for con. venience, I have hitherto omitted. In the first place, the pauses rarely were noticed in the daytimp, and then only during the last few days of the patient's life, but during the night they were extremely well marked, coming on with regularity about eight or nine in the evening, and ceasing towards morning. Secondly, they never occurred when the patient was awake, but he would drop off into a nap, and after a minute or two, more or less, the peculiar form of respiration would commence. Thirdly, towards the termina. tion of the pause twitchings would often, but not always, occur; these were noticed, of course, on the sound side of the body, also occasionally movements of the abdominal parietes mignt be noticed. Fourthly, shaking would not at first break the pause, but if continued it generally took effect. Sometimes on shaking him he would give a short inspiration, and again pass into a state of apnoea. On auscultation the heart sounds, which seemed normal, but rather faint, could be heard plainly alone, and in no way irregular. The pulse could be felt at the wrist beating strongly, and differing in no perceptible degree from that which could be felt during the breathing period. The commencing respiration sounded most peculiar, and could be heard through the stethoscope generally a second or two before there was any outward or visible sign of it. The urine during the early part of the case showed only traces of albumen, and had a specific gravity of 1025, acid reaction. During the latter period of the case there was a great quantity of albumen, and the urine was more scanty. There was no dropsy of any part of face, body, or legs. With regard to remedies, I found none to have much effect. Bromide of potassium and chloral hydrate were totally inert, and the more he slept the worse he was. Nitrite of amyl, on being held to his nostrils, stopped the symptoms temporarily, but only by causing him to wake up, which he invariably did after it had been held to his nose for seven or eight seconds. The nurse reported that on several occasions he was more quiet after its use for the rest of the night, but on others he was as bad as ever.

The following is an account of the post-mortem examina. tion, made on the body the day following death. On remov. ing the skull-cap and dura mater a quantity of fluid escaped, and the posterior surface of cerebrum and cerebellum was congested, especially on the left side. The pia mater was much injected. The substance of the cerebral hemispheres differed little, if at all, from that seen in health. On cpiting into the ventricles the left was greatly distended with blood. clot, and the right contained a small clot and a great quantity of serous fiuid. On washing away the clot the corpus striatum and other portions of the floor of the left ventricle were found to be much softened and disintegrated. The pons and medulla, as far as could be seen with the naked eye, were perfectly normal and heaithy, and, though covered with injected vessels of the pia mater, it was white and healthy on being cut into. There was no softening or disease of any kind apparent in these latter parts. The above were the only lesions to be found in as careful an examination of the contents of the cranium as it was in my power to make. The lungs were congested and œdematous. There was but little fluid in the pericardium. The heart was hypertrophied but little if at all dilated, and the walls were firm and looked healthy, showing no evidence of fatty degeneration that could be detected with the naked eye. The aor ta was of large size, but showed no atheromatons patches. 
There was no valvular disease in the heart, but $I$ found on opening the right ventricle two growths, the one about three-quarters of an inch across, embedded amongst the columir carneæ, and another about an inch in length and half an inch in diameter, attached by a pedicle, and hanging from the wall into the cavity of the ventricle. I also found a smaller growth in the left ventricle, attached to the columnæ. The other viscera were healthy, with the exception of the kidneys, which were both diseased, the right especially so. The granular condition was shown to a slight extent; but the principal point for notice was the presence of a number of cysts varying in size from a hemp-seed to a small marble, and containing a yellow transparent fluid. These were principally found in the cortical portion. The capsules were easily removed, but the kidney was torn at one or two points.

The above is only a poor description of the case ; but I hope it may have presented some points worthy of notice, and which may be acceptable to those taking an interest in the subject. Teignmouth.

\section{FRACTURE OF THE PARIETAL BONE; ATAXIA ; RECOVERY.}

BY JOHN HOSACK FRASER, M.B. EDIN., LATE RESIDENT PHYSICIAN TO THE EDINBURGH ROYAL INFIRMARY.

THE following is the history of a most interesting case, which has recently come under my care, and which appears to me to be worthy of publication.

About two years ago M. W - aged forty-five, was engaged at work when a brick fell on his head, from a height of twelve feet, inflicting a fracture of the posterior superior portion of the right parietal bone. In the course of three weeks he had so far recovered from the effects of that accident as to be able to resume work. For the next fifteen months the only symptom from which he suffered to indicate disease of the brain was occipital headache. About seven months ago he became depressed, taciturn, and apathetic, and complained of giddiness, amblyopia, diplopia, deafness, and loss of memory, from which it was manifest that he was the subject of a grave form of brain disease. A few months later his gait became unsteady and tottering, and his hair was becoming rapidly grey. When he walked he had an inclination to fall forwards or backwards; at other times he moved in a peculiar spiral manner, describing the so-called "circus" movements. About the end of March this ataxia became so much worse that he was unable to sit or stand. Urgent vomiting, a slow and irregular pulse, and drowsiness, accompasied with sleeplessness and delirium, set in. This was his condition when I saw him on March 29th, 1883, and, after making a careful examination on that occasion, I pronounced him to be suffering from a tumour of the cerebellum. 0phthalmoscopic examination revealed double optic neuroretinitis. The right pupil was dilated and semilunar in shape; the left was normal both in size and form. His sensations, sensibility, and reflexes were perfectly normal, and there was an entire absence of motor paralysis.

My reasons for localising the disease to the cerebellum were as follows:-(1) The persistent occipital headache. This probaly pointed to a stretching of the tentorium. (2) Vertigo. (3) Loss of coördination. (4) Amblyopia and diplovit. (5) Deafness. (6) Vomiting, and slowness and irregularity of the pulse. These two last-named symptoms probably pointed to an irritation of the pneumogastric nerve. The slowness and irregularity of the pulse varied distinctly with the headache, being most marked when the headache was most intense, and vice versâ.

As to tre tment, bafore adopting any remedial measures, it was most important to decide the question of syphilis. He denied having had that disease, but, on making an examination, I found a cicatrix on the glins penis and enlaigement of the glauds in both groins. I ordered him onesixteenth of a grain of the perchloride of mercury and $t \in n$ grains of the iodide of potassium three times a day, and at the end of a woek I was surpised to find the great improventent that was apparent in his condition. The roraiting, drowsiness, headache, and delirium had left him; lis memory was decidedjy improved; and his hair, which was previonsly grey, was fat $t$ returning to its natural brown colour. There was, however, no improvement in his coördination. Four days later I found him comfortably seated in his chair, and he could stand with his feet widely apart, but could not walk without tottering and falling. A week later I was much pleased to find that he could stand steadily with closed eyes when both feet were brought closely together, and walk remarkably well.

Birmingham.

\section{THE TREATMENT OF DIABETES INSIPIDUS} BY ERGOT.

BY T. HAMMOND WILLIAMS, L.R.C.P. ED., \&c. SENIOR ASSISTANT MEDICAL OFFICER TO THE TOWN'S HOSPITAL AND ASYLUM, GLASGOW.

THE following notes may be interesting as corroborating recent reseaich in the treatment of this previously intractable disease.

During a short period as resident assistant in the Glasgow Royal Infirmary, I had the opportunity of seeing several cases treated with valerian, and with very discouraging results (Trousseau). Galvanism was equally ineffective. Keeping in mind that there must be increased blood-supply to the kidney, and as this is controlled by the inhibitory branches of the sympathetic, the treatment is obviously one of decreasing the blood-supply through that channel. Of the many agents which act thus, ergot in its various forms seems the most potent. T $T$ wo cases having come under my observation, the feasibility of the above treatment was suggested.

Margaret $\mathrm{Mc} \longrightarrow$, aged fifty-one, widow, washerwoman, was admitted Oct. 21st. 1881. Her trouble commenced about four years ago. She had enjoy ed fair health previously, except an attack of small-pox in her youth. Has had seven children. Was rather intemperate in her habits. The first symptom was thirst, of which she took little notice, until the frequent calls to pass urine compelled her to seek advice. When admitted her urine amounted to 280 ounces daily; sp. gr. 1002, clear, limpid; deposit of phosphates; no albumen. no sugar. Her appearance was pale and emaciated. Heart's action weak and fluttering. Complained of shifting pains, which gave her great annoyance. Skin was extremely parched, and spirits much depressed. Appetite voracious. Bowels regular. Two drachms of the fluid extract of ergot were administered thrice daily, combined with digitalis to steady the heart's action. Under this treatment the improvement was marked and striking, the quantity of urine excreted diminishing in three weeks to 140 ounces. This treatment was continued for another month, with the result of further reducing the quantity to eighty ounces; sp. gr. 1015. The pains disappeared after being only a fortnight under treatment. When the patient felt herself so much improved she left the hospital, notwithstanding my efforts to induce her to remain, promising to return if the symptoms were renewed. I have not since seen her.

Mary - aged forty-nine, widow, hawker. As in the above case, the first sy mptom which attracted attention was increasing thirst, afterwards frequent nightly calls to pass urine, of about four months' duration. When seen her bodily condition was good, appetite fair. Had history of "weak turns" of long standing, and repeated attacks of bronchitis. Heart sounds weak and distant, pulse soft and compressible. Shifting neuralgic pains, with vertigo, were much complained of, which no treatment seemed to benefit. Temperature normal ; family history good. Urine: sp. gr. 1005; acid reaction, no albumen, no sugar, a trace of phosphates. Daily quantity of urine passed was 300 ounces. After failures with tannic, benzoic, and phosphoric acids, I again prescribed ergot, also in combination with digitalis, reducing the quantity of urine in twelve weeks to seventy ounces; sp. gr. 1018.

Although the dose of ergot prescribed was large, no ill effects were produced, excent constipation, to counteract which an occasional purgative was given. The disappearance of the neuralgic pains during the progress of treatment seems to confirm the general idea of the nervous origin of the malady. The disease in the above cases was not traceable to any assignable cause or hereditary taint. Glasgow.

Vaccination Grant. - Dr. Hartley, the union medical officer for Pemberton, has received the Government grant for efficient vaccination. 